\title{
Análisis criptopaleontológico del lapidario de Teofrasto (s. III a.C.)
}

\author{
The cryptopalaeontological analysis of the Teofrasto's lapidary (3th \\ Century B.C.)
}

\author{
J. Carrascoํㅗㄹ E. Liñán¹, M. Liñán², J.A. Gámez Vintaned³ y R. Gozalo³
}

\section{RESUMEN}

La obra "Perì líthon" o "Tratado de Piedras" de Teofrasto, es considerado el texto más antiguo conservado sobre minerales y rocas, aunque haya llegado hasta nosotros incompleto. En este trabajo se analiza su contenido comparándolo con el de otros lapidarios antiguos y se concluye que once de las piedras que refiere y que vienen indicadas con nombres geográficos o crípticos son fósiles de plantas, vertebrados o químicos. Por eso, esta obra debe considerarse también como el tratado más antiguo que conocemos sobre paleontología, pues además de los fósiles que menciona, en ella se alude expresamente al proceso de fosilización.

Palabras clave: Criptopaleontología, Teofrasto, historia de la geología.

\section{ABSTRACT}

The work "Peri líthon" or Teofrasto's "Treatise of stones" has been considered the oldest text still available about minerals and rocks, even though it has remained incomplete. In this paper, the study of its contents shows that eleven of the stones called by geographic or cryptic names are either fossils from plants or vertebrates or chemical fossils. Therefore, the "Perì líthon" should also be considered as the oldest known treatise about palaeontology, because in addition to the fossils mentioned, it refers specifically to the fossilisation process.

Keywords: Cryptopalaeontology, Theophrastus, history of geology.

\section{Introducción}

Los textos sobre las piedras, también llamados lapidarios, son tan antiguos como las civilizaciones (Duffin, 2005). Aunque se encuentran algunas referencias en el Papiro Eber del antiguo Egipto con una antigüedad de 1.500 a.C., es sin duda el desaparecido lapidario de Zoroastro (Siglo VII a.C.) del que sólo nos han llegado referencias a través de Plinio (s. I), uno de los primeros de este tipo de textos.

El más antiguo conservado, aunque parcialmente, es sin duda el "Tratado sobre Piedras" o "Perì lithon" de Teofrasto (Ereso 371-Atenas 287 a.C.). Fue discípulo de Platón y de Aristóteles; a la muerte de este último presidió el Liceo y la escuela peripatética en Atenas. Aunque se dedicó fundamentalmente a la botánica en su faceta médica y escribió un extenso tratado "Sobre las Plantas" y otro "Sobre los Peces", también nos han llegado algunos de sus escritos sobre las piedras como el que estudiamos aquí, que según nos dice el propio autor fue realizado después de otro previo sobre los metales, al que alude en el texto. El lapidario no está completo, según se infiere de su lectura y de las citas de otros

\footnotetext{
1 Área y Museo de Paleontología-IUCA. Departamento de Ciencias de la Tierra. Facultad de Ciencias. Universidad de Zaragoza. 50.009-Zaragoza. Email: linan@unizar.es.

2 Contemporánea S.L. C/ Cruz Roja, 8. León

3 Departamento de Geología. Facultad de Biología. Universitat de València. 46100 Burjasot (Valencia).
} 
autores sobre ciertas piedras que no aparecen en los textos conservados.

La obra conocida se compone de 73 párrafos o epígrafes que fueron traducidos del griego al francés por Fernand de Mely (1909) y al inglés por Caley \& Richards (1956). Aunque hemos tenido en cuenta este último trabajo, hemos realizado sobre la versión francesa nuestro estudio criptopaleontológico que ha sido contrastado, mediante la ayuda del Dr. Cortés Gabaudán, con la más clásica edición de Eichholz (1965). En el estudio se trata de conocer, a través de las descripciones poco precisas que se hacen de las piedras, cuáles de ellas podrían tratarse de fósiles y qué se conocía de ellos. Precisamente la Criptopaleontología se definió como "el estudio de las observaciones paleontológicas ocultas en los textos antiguos y que perviven en las tradiciones orales de los pueblos" (Liñán, 2004, Liñán et al 2011).

El objetivo de este estudio es, por tanto, tratar de identificar de forma razonada los posibles fósiles que se conocían en la Grecia ateniense en tiempo de Aristóteles; cuál era su procedencia y cuál su interpretación como elementos producidos espontáneamente en la naturaleza. En algunas ocasiones, será factible conocer también su empleo social en el mundo griego durante este tiempo.

Primero procederemos a diferenciar los fósiles de esqueletos mineralizados que constituyeron una parte del cuerpo del organismo vivo del que proceden (los fósiles corporales) y a continuación los fósiles químicos o productos degradados de materia orgánica procedentes de antiguos seres vivos, que se han conservado mediante su fosilización como rocas orgánicas. Para la localización de cada piedra en el texto pondremos una $\mathrm{T}$ aludiendo a Teofrasto y a continuación el número de epígrafe en que se encuentra.

Posteriormente, analizaremos la interpretación de los fósiles que hace Teofrasto.

\section{Fósiles vegetales}

\section{Piedra de madera podrida (T17)}

"A veces se encuentra, en las minas de Scaptisyle, una piedra que recuerda a la madera podrida, que cuando uno vierte aceite por encima se quemaba y cuando se extinguía el fuego, la piedra no había sufrido ninguna modificación".

Probablemente se refiere a madera fósil normalmente conservada por permineralización de sílice en cuarzo, mineral muy brillante a la luz, el cual suele contener minerales contaminantes como es el caso de los rojo-violáceos de la variedad amatista o negra del cuarzo ahumado; la conservación en ópalo es muy rara. En el área mediterránea es frecuente la presencia de troncos de la familia de las pináceas fosilizados en sílice procedentes de estratos del Cretácico y Terciario. En España son abundantes en la facies Utrillas del Cretácico de Teruel. En Estados Unidos son famosos los yacimientos de troncos de cuarzo donde abundan, entre otros, los de la familia de las araucáceas (Auracaryoxilum arizonicum) procedentes de la Formación Chinle del Triásico de Arizona, normalmente fracturados y a los que los indios americanos consideraban despojos de las lanzas arrojadas desde el cielo por los dioses (Mayor, 2000). No podemos descartar fehacientemente que se trate de una referencia al asbesto, un grupo de minerales metamórficos que son ignífugos y cuya disyunción se da, en algunos casos, bajo forma de agujas y pudiera recordar lejanamente a madera seca, pero como también argumentan Caley \& Richards (1956) este mineral no se encuentra en esta localidad griega, por lo que para ellos esta piedra sería un lignito.

\section{Kalamos Indikos petrificado (T38)}

"De alguna manera, el <kálamos indikós $>$ petrificado no se diferencia demasiado [del coral ramificado], pero todo esto será objeto de otro examen".

El kálamos indikós (del griego kálamos; caña e indikós; índico) debe referirse al bambú o Indocalamus. El género Indocalamus pertenece a la familia de las poáceas y consta actualmente de varias especies. También el género Calamus es una planta actual que incluye varias especies de palmeras trepadoras, pero la cita de Teofrasto, por su descripción y etimología, parece referirse más a un fósil vegetal ramificado y con el tronco en forma de caña.

Seguramente se trata de una alusión a fósiles de equisetos muy frecuentes y extendidos en el registro fósil (Devónico-actualidad) y entre los que se encuentra el género Calamites. Aunque Jenófanes de Colofón (siglo VI a. C.) ya refiriera plantas fósiles ("hojas de laurel") en las rocas de Paros (Zittel, 1899), con esta piedra de Teofrasto seguramente nos encontremos ante la primera referencia escrita sobre equisetos fósiles, que data ya de principios del siglo III a. C. 


\section{Fósiles de vertebrados}

\section{Piedra Porosa Quemada (Arábiga) (T19-20)}

"No obstante, hay personas que creen que la piedra pómez se forma necesariamente por el fuego, salvo la que se forma a veces de la espuma de la mar; esta creencia les viene por la observación, tanto a causa de las piedras encontradas alrededor de los cráteres como de la piedra porosa que cambia a pómez cuando es quemada...".

Mely (1909) traduce el nombre de esta piedra como "arábiga". Según Caley \& Richards (1956) esta piedra podría referirse a alguna toba volcánica más que a la piedra arábiga de acuerdo con la distinta transcripción del nombre griego de la piedra (porosa o arábiga, según manuscritos). La piedra arábiga quemada tiene gran parecido con la piedra pómez o pumita y su mismo uso farmacológico. La Piedra arábiga se ha relacionado profusamente desde Plinio (siglo I) con el marfil fósil (Liñán 2005b). Dioscórides (siglo I) alude a la piedra arábiga quemada como dentífrico, separándola del marfil actual (Liñán, 2005c). Seguramente, se trata de marfil fósil quemado que circulaba en la antigüedad y se encuentra en múltiples tratados de farmacopea hasta el siglo XVII bajo el nombre de piedra arábiga (Liñán, 2005d).

También hay una referencia a la piedra pómez que se forma de la espuma de la mar que debe corresponder a la carcasa de ciertas esponjas que se parecen a la piedra pómez y también fueron utilizadas en el aseo personal o como dentífricos y a la que Dioscórides describe como la quinta especie de alcionio: "La quinta [especie de <alkyónion>] se parece, por su forma, a un hongo, es inodora y áspera por dentro, y, hasta cierto punto, parecida a la piedra pómez".

\section{Marfil fósil (T37)}

"He aqui casi las más bellas piedras. Hay entre otras: tal como el marfil fósil <Eléphas oryktós $>$ de color variegado, con negro y blanco".

Es una clara referencia a esqueletos de proboscídeos fósiles encontrados al remover los estratos que los contienen (Caley \& Richards, 1956). Se puede incluir en la denominación generalizada de Piedra Arábiga tan frecuente en los lapidarios, y cuya primera referencia en lengua española se encuentra en el "Libro de las Piedras" del Rey Alfonso X "El sabio" de Castilla traducido en el siglo XIII de un texto original caldeo, (Brey Mariño, 1997) pero en el que los traductores incluyeron referencias propias de algunas piedras en España (Liñán, 2006).

\section{Piedra de Huesos \\ (Teofrasto, in Plinio XXXVI, 134)}

Sólo se encuentra citada por Plinio, de pasada y sin ninguna descripción. Este autor dice que la toma de Teofrasto.

La Piedra de Huesos es citada por primera vez en español en el lapidario de Alfonso X "El sabio" (Alfonso I 13 37) como piedra que atrae los huesos y es útil en polvos para soldar fracturas óseas (Liñán et al. 2011).

\section{Fósiles químicos}

\section{Piedra Spinus (T13)}

"La piedra llamada spinus <spínos>, que se encuentra en esas minas, fragmentada, abandonada a su propia suerte colocada al sol, se quema espontáneamente y más cuando se la humedece o se la rocía con agua”.

Aunque pudiera tratarse de algún tipo de carbón o turba, quizá en forma de astillas, que puede arder a altas temperaturas, Caley \& Richards (1956) argumentan que debe ser algún tipo de asfalto bituminoso que arde espontáneamente al sol, lo cual es coherente.

\section{Carbón (T16)}

"Estas piedras que sacan excavando por su utilidad se llaman carbón y son de naturaleza terrosa. Ellas prenden y el fuego las consume como los carbones vegetales. Se las encuentra en Liguria en el mismo lugar que el ámbar y también en Elea yendo hacia Olimpia a través de las montañas. Los que trabajan los metales fundidos las usan".

Seguramente se refiere la Piedra de Gagates identificada con el azabache y referida por primera vez en los lapidarios apócrifos griegos: "Órfico" (474-493), "Kerygmata" (17) y "Damigeron-Évax" (LXXII) del siglo II a. C. (Liñán, 2005a). Véase también una referencia al carbón en Ebers (51 5 y 197 39) del 15.000 a.C.; Plinio (XXXVI 141-142) del siglo I; Dioscórides (V 128) del siglo I; Isidoro (VI 4.3) del siglo 
VII; Alfonso X (I 2,3 y I 67, 212) del siglo VII. El ámbar se encuentra en todas las minas de carbón lo que corrobora la asignación.

\section{Piedra de Bina (T12)}

T12: "Entre las piedras frágiles, algunas de ellas puestas al fuego, llegan a ser como los carbones ardientes y quedan asi durante largo tiempo. Tales son las de las minas de los alrededores de Bina, acarreadas por el río: se queman cuando se colocan encima de ellas carbones vegetales encendidos y lo hacen mientras uno sopla, después se debilita [su combustión] y de nuevo pueden arder: Es por esto que pueden servir durante largo tiempo. Su olor es completamente insoportable y asfixiante".

Se tratarían de rocas siliciclásticas organógenas con cierta proporción de azufre lo que les daría una combustión lenta y el característico olor fétido y asfixiante. Caley \& Richards (1956) la consideran también como una sustancia natural bituminosa y sólida.

\section{Piedra de Erineas (T15)}

T15: "La piedra que se encuentra en el promontorio de Erineas se quema igual que las de Bina, exhala un olor a asfalto (betún) y dejan después de quemadas un residuo que recuerda a la tierra calcinada".

Se debe referir al betún de Judea o asfalto que se menciona en la Biblia y es también llamado betún asfáltico. Era conocido desde las primeras civilizaciones y apreciado por sus cualidades aislantes, aglutinantes y medicinales (Carrasco et al. 2011). Se encuentra citado específicamente como remedio farmacológico ya en la "Materia Médica" de Dioscórides (I 73) y las "Etimologías" de Isidoro de Sevilla (XVI 2.1).

\section{Ámbar $(T 16,28,29)$}

T16: "Se las encuentra en Liguria donde nace también el ámbar".

T28: "...atrae [posee electricidad estática] como la piedra de ámbar".

T29: "El ámbar es también una piedra porque se la extrae excavando en Liguria; como la precedente [Piedra de Lince] tiene el poder de atraer, que se manifiesta sobre todo con mucha evidencia en la piedra que atrae el hierro [magnetita]".

El ámbar es probablemente la piedra más citada por los autores griegos y latinos (Esquilo, Filoxeno, Eurípides, Nicandro, Sátiro, Cares, Filemón, Demostrato, Zanotemis, Sudines, Metrodoro, Sótaco, Piteas, Timeo, Nicias, Teocresto, Jenócrates, Asarubas, Mnaseas, Ctesias, Mitrídates, Teomenes, Sófocles y Calistrato). A lo largo del tiempo recibió diferentes denominaciones: élektron, electrum, lyncurium, langurium, sucinum, thium, sacrium, sacal y glaesum (Plinio XXXVII 30-51).

\section{Piedra Orina del Lince (T18)}

"Ella es excelente por sus virtudes como la piedra orina del Lince <lyngourion> pues sirve igualmente para entallarlas; esta última es muy dura como una piedra, atrae como el ámbar. Se dice incluso que no sólo atrae las briznas de paja y de madera sino las de cobre y de hierro si son muy menudas. Así lo afirma Diocles. Es muy transparente y fría. Es mejor la producida por los animales salvajes que por los domésticos, por los machos que por las hembras: Ella varía también según la nutrición, el trabajo o el reposo, y finalmente siguiendo la naturaleza misma de los cuerpos, según que uno sea más seco y el otro más húmedo. Los que están habituados, la encuentran bajo tierra pues cuando deja su orina, el animal la oculta y la recubre de tierra. Exige mucho trabajo su manufactura".

Esta piedra deriva de lynx (lince) y oúrion (orina) según Gauban (com. escrita), Se la conoce en lapidarios posteriores como Piedra de Lince que es formada cuando su orina se coagula. Para Plinio no es sino una variedad de ámbar, lo que explicaría su transparencia, color, dureza y su uso en sortijas pues no es fácil de tallar por su facilidad en fracturarse. Caley \& Richards (1956) también la consideran como un posible ámbar. En la Edad Media los belemnites fueron incluidos en la Piedra de Lynce (Duffin, 2006) pero es difícil pensar que un frágil belemnites, externamente opaco pueda ser entallado en una sortija o como piedra preciosa en un colgante; y menos aún que la calcita, mineral del que está compuesto este fósil, atraiga nada. Como falsos belemnites es también considerada esta piedra por Caley \& Richards (1956).

En resumen, del análisis criptopaleontológico podemos concluir que, aunque hay referencias más antiguas aisladas sobre fósiles en los autores clásicos 
griegos (Zittel, 1899, Mayor, 2000), las once piedras interpretadas como fósiles hacen que "Peri lithon" suponga un pequeño tratado sobre paleontología.

Como adición a la esta lista de fósiles podemos incluir dos fragmentos de la obra de Teofrasto traducidos por G. Bouillet-Roy (Ellemberger, 1988) que contienen nuevas piedras fósiles. El fragmento (XXX 3) cita la presencia de fósiles invertebrados como consecuencia de las invasiones marinas "Como pruebas de la antigua submersión por las aguas del mar, han quedado depositados cantos rodados, conchas, y varios objetos por el estilo de los que habitualmente son lanzados con la espuma sobre las orillas del mar". Teofrasto también cita peces fósiles del Ponto y Plafagonia en su obra "Sobre los peces". El fragmento (CLXXI), que también pueden seguirse en la versión clásica griega de Wimmer (1866) dice: "Pero es algo mucho más especial, al compararlo, y desprovisto de explicación, lo que se refiere a los peces fósiles <criktous ichtys> de Paflagonia. Se dice que alli se encuentran en profundidades mucho más considerables perfectos y en abundancia. Ahora bien, este lugar no ha sufrido inundaciones fluviales ni se han reunido en él las aguas". Este texto sobre los peces fósiles de Paflagonia, ya citados previamente por Eudoxo de Cnido (¿408?-¿347? a. C.), ha servido de referencia para considerar clásicamente a Teofrasto como partidario de un origen inorgánico de los fósiles (Ellenberger, 1988, 35). Sin embargo, como se puede leer en el texto conservado, Teofrasto no indica en él la génesis de estos peces sino sólo que le extraña la profundidad a la que se hayan y que desconoce su explicación. Además, a continuación del texto citado, Teofrasto dice: "a partir de eso, decimos, que los huevos y los principios de la vida <génesis> son abandonados (allî)" en clara referencia a un origen orgánico de los fósiles (Cortés Gabaudán com.per. escrita). En los fragmentos de su obra "Perì líthon" sí que encontramos una clara referencia a su interpretación de los fósiles, como veremos a continuación.

\section{Interpretaciones geológicas y paleontológicas del texto conservado}

El libro de las piedras de Teofrasto se diferencia bien de los otros lapidarios conocidos porque es el primero en tratar de las propiedades de las piedras (dureza, densidad, transparencia, brillo, solubilidad, combustión, fusión, grabado, tallado, disposición en capas o aisladas), y de plantearse e intentar conocer su génesis, al tiempo que da variadas referencias de su procedencia geográfica. Esta intención al escribirlo, lo diferencia bien de la "Historia Natural" de Plinio (Siglo I) que tiene como objetivo dar una compilación de los diferentes nombres que se otorgan a las piedras según su procedencia geográfica y cultural, y de las creencias que se tiene sobre algunos supuestos poderes mágicos, para ponerlos en duda. También se diferencia de la "Materia Médica" de Dioscórides (Siglo I) en que no pretende referir el uso médico de las piedras. Es por tanto el primer tratado con pretensiones científicas de mineralogía (Amorós \& Tavira, 1983), de petrología, y de paleontología que nos ha llegado hasta nosotros, aunque sólo sea una pequeña parte. Tampoco hay en él reminiscencias astrológicas tan frecuentes en los lapidarios orientales pues carecían de toda consideración racional para la escuela peripatética.

Para Teofrasto todas las piedras proceden: o bien del agua o bien de la tierra. En el primer origen incluye a los metales y en el segundo al resto que denomina piedras más comunes y nobles. Todas proceden de una materia pura y homogénea en origen que se va diferenciando por diversos métodos como el flujo, la filtración o la separación. La petrificación o solidificación (concreción en el texto) se forma unas veces por calor y otras por el frío; e incluso por ambas causas. Las que se funden como los metales son para él de naturaleza húmeda mientras que las que resisten al fuego, quebrándose, son de naturaleza seca. Estas dos propiedades han quedado reflejadas en las descripciones de las piedras de la mayor parte de los lapidarios posteriores hasta la Edad Media.

Respecto a las consideraciones paleontológicas, cuestión principal que nos atañe en este trabajo, cabe resaltar las ideas del autor expresadas sobre la formación de los fósiles: "Hay otras [piedras] que petrifican todo lo que se mete dentro de ellas" (T9). Con esta frase viene a indicar que los fósiles con aspecto de animales o plantas tan conocidos y referidos por la escuela presocrática, serían animales o plantas fosilizados. Teofrasto debe, por todo lo expuesto aquí, ser reivindicado como partidario de un origen biológico para los fósiles y exponente de una escuela que interpreta que la fosilización ("petrificación") de los organismos biológicos puede producirse cuando quedan enterrados o envueltos en ciertas otras piedras que tienen (se dan las) condiciones para ello.

La fosilización en superficie, que es común observar hoy en las fuentes con aguas ricas en carbonato cálcico al envolver los vegetales y animales del 
entorno produciendo travertinos, era bien conocida en el mundo clásico como lo demuestra la cita de Ovidio (XV 313-314) en su obra "Metamórfosis" acerca de "un río de los Cicones cuyas aguas convierten en piedra las entrañas de los que las beben y todas las demás cosas las empedernecen" (Torrubia, 1785).

Este origen biológico de los fósiles, ya sea como restos de organismos marinos procedentes de antiguas inundaciones o ya como restos conservados al ser envueltos por las rocas, se encuentran en todas las obras de los filósofos presocráticos como Anaximandro (610-547 a.C.) en su obra "Acerca de la Naturaleza", referido por Aecio, Plutarco, Censorino e Hipólito; Pitágoras (580-500 a.C.), citado por Ovidio (43 a.C.-h.17 d.C) en "Las metamorfosis"; Jenófanes de Colofón (¿570?- ¿475? a.C.) en "Sobre la Naturaleza" citado por Estobeo, Aecio y Polux; Anaxágoras de Claxomene (500-428 a.C.), referido por Hipólito; Janto de Lidia (Siglo V a.C.), citado por Eratóstenes (276-196 a.C.), referido a su vez por Estrabón; Herodoto (484-425) en su "Historia" y Jenofonte (427355 a.C). Por eso, todo el legado griego influenciado fundamentalmente por los filósofos presocráticos y aristotélicos transmitió una interpretación, a los numerosos cuerpos fósiles que se encontraban en la región mediterránea, como antiguos organismos conservados en el interior de las rocas de la corteza terrestre de acuerdo con Edwards (1967), Rudwick (1972) y Liñán (1998), con la única excepción del filósofo Platón.

\section{AGRADECIMIENTOS}

El Dr. Francisco Cortés Gabaudán de la Universidad de Salamanca realizó sugerencias e importantes precisiones a la traducción del texto original griego que han mejorado sensiblemente este trabajo. A los Doctores Roberto Wagner del Museo Paleobotánico del Jardín Botánico de Córdoba y José Manuel López Pérez de la Universidad de Zaragoza por sus comentarios al manuscrito original. Agradecemos a Isabel Pérez Urresti (MEC.Universidad de Zaragoza) su ayuda técnica. Este es un trabajo realizado dentro del Proyecto CGL2011-24.516 del Ministerio de Educación y Ciencia.

\section{Referencias}

Amorós, J.L. \& Tavira, P. (1983). Los orígenes de la mineralogía. El Peri Lithon de Teofrasto. Revista de materiales y procesos geológicos. 1: 55-80.

Brey Mariño, M. (1997). El lapidario del Rey Alfonso X el Sabio. Editorial Castalia, Madrid, 275 pp.
Caley, E.R. \& Richards, J.F. C. (1956). Teophrastus on Stones. Graduate Shools The Ohio State University. Columbus. Monographs. Contributions in Physical Science 1, $238 \mathrm{pp}$.

Duffin, C.J. (2005). The western lapidary tradition in early geological literature: medicinal and magical minerals. Geology Today, 21 (2): 58-63. doi:10.1111/j.1365 2451.2005.00491.x

Duffin, C.J. (2006). Stones for the Stone: minerals and fossils in the treatment of renal calculi. Pharmaceutical historian, 36 (4): 56-60.

Eichholz, D.E. (1965). Theophrastus. De lapidibus. Clarendon Press, Oxford, $141 \mathrm{pp}$.

Edwards, W.N. (1967). The early history of Palaeontology. Trustees of the British Museum (Natural History), $58 \mathrm{pp}$.

Ellenberger, F. (1988). Histoire de la Géologie. Tome 1. Des Anciens à la première moitié du XVIIe siècle. Edición española: Historia de la Géología. Volumen 1. De la Antigüedad al siglo XVII. Editorial Labor, 1989, 282 pp.

Liñán, E. (1998). Los fósiles y el pensamiento paleontológico. La interpretación histórica de los fósiles. Discurso de Ingreso en la Real Academia de Ciencias Exactas, Físicas, Químicas y Naturales de Zaragoza, Zaragoza, $34 \mathrm{pp}$.

Liñán, E. (2004). Fósiles, mitos y leyendas: Criptopaleontología. Revista de la Real Academia de Córdoba, de Ciencias, Bellas Letras y Nobles Artes, 146: 189-205.

Liñán, E. (2005). La Criptopaleontología en los lapidarios apócrifos griegos. Revista española de Paleontología, 20 (2): 119-126.

Liñán, E. (2005b): Citas criptopaleontológicas en la obra "Plantas y remedios medicinales" de Dioscórides (siglo I). Revista de la Real Academia de Ciencias de Zaragoza, 60: 133-142.

Liñán, E. (2005c). Una visión criptopaleontológica del lapidario de Plinio "El viejo" (siglo I). Boletín de la Real Academia de Córdoba, de Ciencias, Bellas Letras y Nobles Artes, 148: 119-234.

Liñán, E. (2005d). Fósiles y magia en el año de publicación del Quijote: el lapidario del aragonés Gaspar de Morales "De las virtudes y propiedades maravillosas de las piedras preciosas" (1605). Naturaleza Aragonesa, 14: 4-14.

Liñán, E. (2006). Criptopaleontología y terapeútica contenida en el lapidario del rey Alfonso X "El Sabio" (1279). El primer tratado de literatura paleontológica en lengua castellana. Revista de la Real Academia de Ciencias de Zaragoza, 61: 147-179.

Liñán, E.; Liñán, M. \& Carrasco, J. (2011). Cryptopaleontology: The fossils contained in ancient lapidaries and their magico-medicinal use. In: A history of Geology and Medicine. Abstracts book. (Moody, R.T.J., Duffin, C. \& Gardner-Thorpe, C., eds.) History of Geology Group, Geological Society, London, 25-26.

Mayor. A. (2000). The First Fossil Hunters. Princeton University Press. (Traducción española por R. Martínez i Muntada): El secreto de las ánforas. Editorial Grijalbo, Barcelona, 2003, 429 pp. 
Mély, F. de. (1909). Théophraste. Le libre des pierres. "Perí líthon". Oeuvre numérisée par Marc Szwajcer. In: Les lapidaires. De l'Antiquité et du Moyen Age. Tome II, $1^{\circ}$ fasc: Les lapidaires grecs (Mély, F. de, ed.), Ernest Leroux, Paris, 1-15.

Torrubia, J. (1754). Aparato para la Historia natural española, Imprenta de los herederos de D. Agustín de Gorjuela Sierra. Madrid. Facsímil editado por la Sociedad Española de Paleontología en 1992, 204 pp.

Wimmer, F. (1866). Theophrasti Eresti opera, quae supersunt, omnia. Didot, Paris. (Repr. de 1964, Francfort).
Zittel, K. (1899). Geschichte der Geologie und Pälaontologie bis Ende des 19 Jahrunderts. Edic. inglesa, History of Geology and Paleontology to the End of Nineteenth Century. Walter Scott. London, 1901. Reprint in 1962 by Cramer Publisher, Winheim, Germany, $562 \mathrm{pp}$.

Recibido el 25 de enero de 2012

Aceptado el 10 de julio de 2012 Publicado online el 15 de febrero de 2013 
